\title{
Exacerbation of Retinal Degeneration and Choroidal Neovascularization Induced by Subretinal Injection of Matrigel in CCL2/MCP-1-Deficient Mice
}

\author{
Defen Shen ${ }^{\mathrm{a}}$ Rong Wen ${ }^{\mathrm{b}}$ Jingsheng Tuo ${ }^{\mathrm{a}}$ Christine M. Bojanowski ${ }^{\mathrm{a}}$ \\ Chi-Chao Chan ${ }^{a}$ \\ a Laboratory of Immunology, NEI/NIH, Bethesda, Md., and ${ }^{b}$ Department of Ophthalmology, \\ University of Pennsylvania, Philadelphia, Pa., USA
}

\section{Key Words}

Neovascularization - Retinal degeneration $\cdot$ CCL2 •

Matrigel $\cdot$ Macular degeneration, age-related

\begin{abstract}
This study presents a mouse model for human age-related macular degeneration (AMD) as characterized by subretinal deposit and choroidal neovascularization. Matrigel, a basement membrane extract, solidifies after implantation in tissue and can stimulate local angiogenesis. This study demonstrates the induction of neovascularization and focal retinal degeneration following subretinal Matrigel injection in mice. In senescent mice, the normal functioning of CC chemokine CCL2/MCP-1 and its receptor CCR2 confers protection against age-related retinal degeneration, a disease that shares many similar features with human AMD. Our data shows that CCL2-deficient mice develop more severe disease as compared to the wild-type controls. These findings suggest that Matrigel subretinal injection could be used to generate AMDlike pathological changes. The data support the previously proposed role of CCL2 in AMD pathogenesis.
\end{abstract}

Copyright $\odot 2006$ S. Karger AG, Basel

Age-related macular degeneration (AMD) is one of the leading causes of severe visual impairment among the elderly in the developed world [1]. Although the clinical characteristics and histopathology are well described, the pathogenesis of this complex disease is not yet fully understood [2, 3]. Drusen development in the macula, a hallmark feature of early AMD, can be accompanied by choroidal neovascularization (CNV) or geographic atrophy. Currently, there are two types of animal models used in AMD studies. These models involve animals with $\mathrm{CNV}$ and retinal atrophy either induced by (1) physical or chemical stimulation by light, laser, or lipid diet [4-6] or (2) congenital [7] or genetic engineering [8-12]. This study presents the retinal degeneration and neovascularization induced by subretinal injection of Matrigel and compares the pathology in CCL2/monocyte chemoattractant protein 1 (MCP-1)-deficient (KO) mice and wildtype (WT) controls.

Two independent experiments were performed according to the tenets prescribed in the ARVO Statement for the Treatment of Animals in Ophthalmic and Vision Research. The 6- to 8-week-old KO and WT mice were bred from two original pairs generously provided by Dr. Bao Lu and Dr. Barrett Rollins (Children's Hospital, Harvard Medical School). The liquid Matrigel (75\% v/v; BD Biosciences, Bedford, Mass., USA) was prepared using phosphate-buffered saline (PBS) at $4^{\circ} \mathrm{C}$. A total of $11 \mathrm{KO}$ and 11 WT mice were subretinally injected with Matrigel in both eyes under general anesthesia. After exposing the sclera, an incision was made between the limbus and the equator using a sharp No. 33 size needle. The Matrigel suspension $(0.5 \mu l$ per eye $)$ administered via a Hamilton

\section{KARGER \\ Fax +4161306 1234 E-Mail karger@karger.ch} www.karger.com
(C) 2006 S. Karger AG, Basel 0030-3747/06/0382-0071\$23.50/0

Accessible online at: www.karger.com/ore
Chi-Chao Chan, MD

Bldg. 10, Rm. 10N103, NEI/NIH

10 Center Drive

Bethesda, MD 20892-1857 (USA)

Tel. +1 301406 0417, Fax +1 301402 8664, E-Mail chanc@nei.nih.gov 

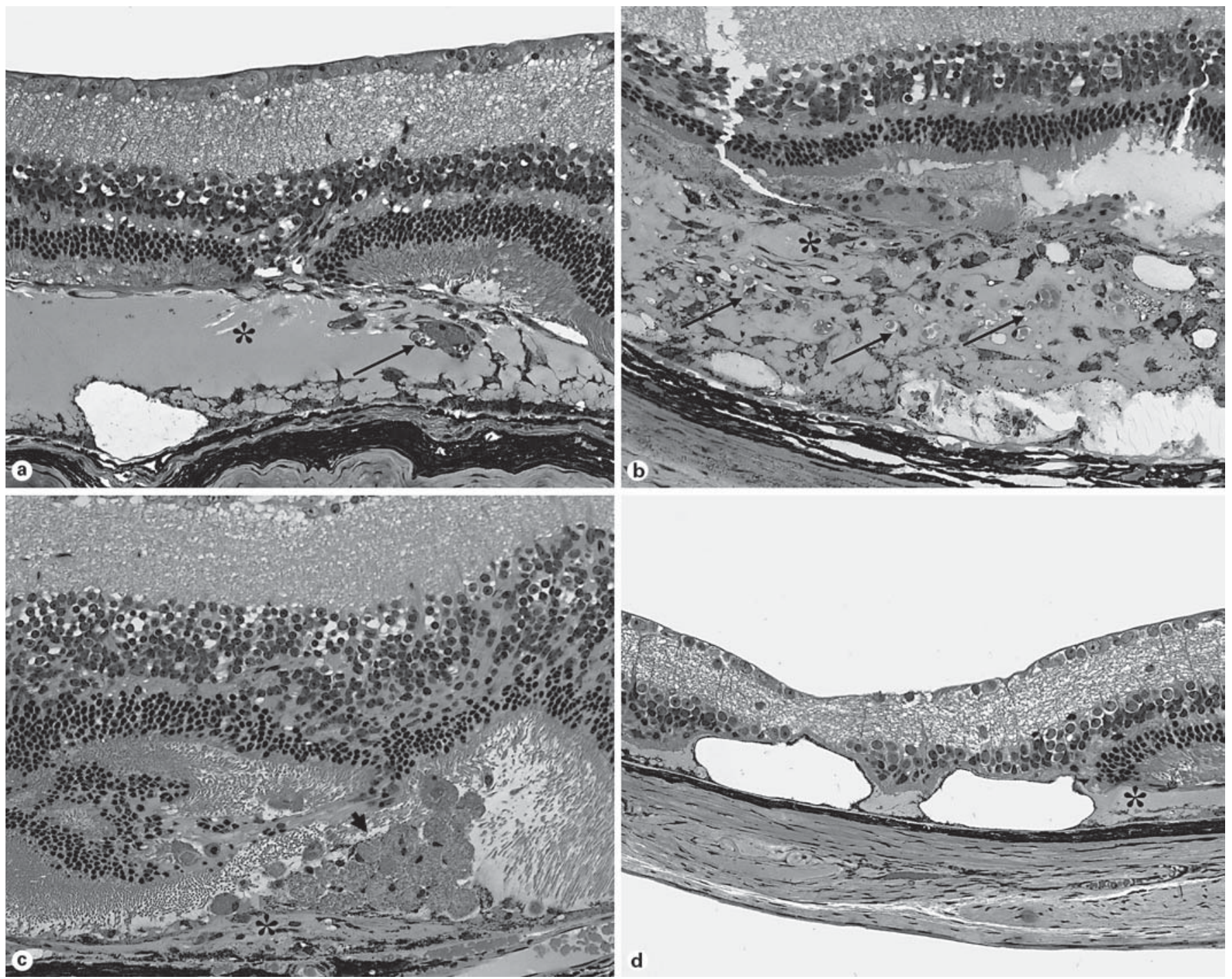

Fig. 1. Microphotographs showing Matrigel (*) in the subretinal space above degenerative RPE and photoreceptor cells. a Neovascular vessels (arrow, CNV) are induced in the Matrigel implant of a WT mouse. b Many small choroidal neovascular vessels (arrows) are observed in a CCL2 KO mouse. c An aggregation of macrophages (arrowhead) with small residue Matrigel is found in a WT mouse. d A focus of total photoreceptor cell loss mimics geographic AMD in a KO mouse. Hematoxylin and eosin. Original magnification $\times 200$.

microsyringe with a No. 33 blunt tip needle was slowly injected into the subretinal space along the previous needle tract. Following injection, the Matrigel polymerized to form a solid gel. Funduscopy was performed every other week and the mice were euthanized at week 4 (4 mice) and 12 (18 mice) postinjection. The eyes were harvested, fixed in 10\% formalin, embedded in methacrylate and sectioned via the injection site for histological examination.
The two experiments reproduced similar data. Dilated funduscopic examination demonstrated subretinal or retinal lesions located in the far periphery. Vitreous hemorrhages were observed in 3/44 (2 KO, 1 WT) eyes. By week 12 , the vitreous hemorrhages had dissolved in two of the three eyes. Histology of the eyes at 4 weeks postinjection demonstrated solid Matrigel located beneath the retina and above Bruch's membrane peripherally. At 12 weeks, Matrigel was observed either beneath or above the retinal pigment epithelium (RPE) below the neuroretinal layers. 
RPE and/or photoreceptor degeneration, RPE migration, and various degrees of $\mathrm{CNV}$ were also observed (fig. 1a). Damage to the RPE cells and photoreceptors was observed in both groups. However, the retinal degeneration was exacerbated in the KO mice as compared to WT mice with the greatest differences found among the 12 weeks' postinjected mice. Furthermore, more KO (53.3\%) than WT (30.7\%) mice developed CNV (fig. 1b). Some of the lesions were accompanied by mild inflammation and macrophage infiltration (fig. 1c). Interestingly, fewer macrophages were found in the KO as compared to the WT mice (fig. 1d).

Matrigel is a solubilized basement membrane preparation extracted from Engelbreth-Holm-Swarm mouse sarcoma [13]. The major components of Matrigel are laminin, collagen IV, heparan sulfate proteoglycans, entactin and nidogen. Once the cold liquid Matrigel is introduced into tissue, it solidifies thus permitting host cell penetration as well as the formation of new blood vessels. A Matrigel-based in vivo angiogenesis assay has previously been standardized for the assessment of neovascularization $[14,15]$. Our study demonstrates that CNV and photoreceptor degeneration can be induced by Matrigel.

CCL2, a member of the MCP group of CC chemokines, is produced by immune and nonimmune cells including the RPE in response to various stimuli such as
TNF- $\alpha$, IL-1 $\beta$, and VEGF. CCL2 KO mice demonstrate impaired in vivo macrophage recruitment $[16,17]$, which may result in disabled degradation and removal of the subretinal Matrigel. Impaired deposit degradation may cause more severe lesions such as CNV and greater photoreceptor degeneration in these mice as compared to the WT. Ambati et al. [2] reported that KOs of CCL2 or its cognate CC receptor CCR2 develop cardinal features of AMD including the accumulation of lipofuscin in, and drusen beneath, the RPE, photoreceptor atrophy, and $\mathrm{CNV}$. Our data supports the hypothesis that macrophage dysfunction may play a role in AMD pathogenesis.

We propose that subretinal Matrigel injection can be used as a model for focal outer retinal degeneration and CNV. Since retinal degeneration and CNV are morphological features of AMD, this model may potentially be useful in studying the mechanisms, such as those involved in inflammatory and immune responses, underlying disease pathogenesis by providing more detailed information concerning the microenvironment infiltrating the Matrigel. Studies on macrophage activity, chemotaxis, and infiltration into the Matrigel would be interesting and should be considered for future investigation. A working model such as this may lead to advances in the screening of antiangiogenic or other therapies for AMD.

\section{References}

1 la Cour M, Kiilgaard JF, Nissen MH: Age-related macular degeneration: epidemiology and optimal treatment. Drugs Aging 2002;19:101133.

$\checkmark 2$ Ambati J, Ambati BK, Yoo SH, Ianchulev S, Adamis AP: Age-related macular degeneration: etiology, pathogenesis, and therapeutic strategies. Surv Ophthalmol 2003;48:257-293.

3 Zarbin MA: Current concepts in the pathogenesis of age-related macular degeneration. Arch Ophthalmol 2004;122:598-614.

$\checkmark 4$ Wenzel A, Grimm C, Samardzija M, Reme CE: Molecular mechanisms of light-induced photoreceptor apoptosis and neuroprotection for retinal degeneration. Prog Retin Eye Res 2005;24:275-306.

-5 Ryan SJ: The development of an experimental model of subretinal neovascularization in disciform macular degeneration. Trans Am Ophthalmol Soc 1979;77:707-745.

$\checkmark 6$ Dithmar S, Sharara NA, Curcio CA, Le NA, Zhang Y, Brown S, Grossniklaus HE: Murine high-fat diet and laser photochemical model of basal deposits in Bruch membrane. Arch Ophthalmol 2001;119:1643-1649.

> Umeda S, Ayyagari R, Allikmets R, Suzuki MT, Karoukis AJ, Ambasudhan R, Zernant J, Okamoto H, Ono F, Terao K, Mizota A,
Yoshikawa Y, Tanaka Y, Iwata T: Early-onset macular degeneration with drusen in a cynomolgus monkey (Macaca fascicularis) pedigree: exclusion of 13 candidate genes and loci. Invest Ophthalmol Vis Sci 2005;46:683-691.

$>8$ Miller JW: Vascular endothelial growth factor and ocular neovascularization. Am J Pathol 1997; 151:13-23.

9 Baffi J, Byrnes G, Chan CC, Csaky KG: Choroidal neovascularization in the rat induced by adenovirus mediated expression of vascular endothelial growth factor. Invest Ophthalmol Vis Sci 2004;1:3582-3589.

10 Ambati J, Anand A, Fernandez S, Sakurai E, Lynn BC, Kuziel WA, Rollins BJ, Ambati BK: An animal model of age-related macular degeneration in senescent $\mathrm{Ccl}-2-$ or Ccr-2-deficient mice. Nat Med 2003;9:1390-1397.

11 Hahn P, Qian Y, Dentchev T, Chen L, Beard J, Harris ZL, Dunaief JL: Disruption of ceruloplasmin and hephaestin in mice causes retinal iron overload and retinal degeneration with features of age-related macular degeneration. Proc Natl Acad Sci USA 2004;101:13850-13855.

12 Karan G, Lillo C, Yang Z, Cameron DJ, Locke KG, Zhao Y, Thirumalaichary S, Li C, Birch DG, Vollmer-Snarr HR, Williams DS, Zhang $\mathrm{K}$ : Lipofuscin accumulation, abnormal elec- trophysiology, and photoreceptor degeneration in mutant ELOVL4 transgenic mice: a model for macular degeneration. Proc Natl Acad Sci USA 2005;102:4164-4169.

13 Passaniti A, Taylor RM, Pili R, Guo Y, Long PV, Haney JA, Pauly RR, Grant DS, Martin GR: A simple, quantitative method for assessing angiogenesis and antiangiogenic agents using reconstituted basement membrane, heparin, and fibroblast growth factor. Lab Invest 1992;67:519-528.

14 Akhtar N, Dickerson EB, Auerbach R: The sponge/Matrigel angiogenesis assay. Angiogenesis 2000;5:75-80.

15 Albini A, Benelli R, Noonan DM, Brigati C: The 'chemoinvasion assay': a tool to study tumor and endothelial cell invasion of basement membranes. Int J Dev Biol 2004;48:563-571.

16 Kuziel WA, Morgan SJ, Dawson TC, Griffin S, Smithies O, Ley K, Maeda N: Severe reduction in leukocyte adhesion and monocyte extravasation in mice deficient in CC chemokine receptor 2. Proc Natl Acad Sci USA 1997;94: 12053-12058.

17 Tuaillon N, Shen DF, Berger RB, Lu B, Rollins BJ, Chan CC: MCP-1 expression in endotoxininduced uveitis. Invest Ophthalmol Vis Sci 2002;43:1493-1498. 